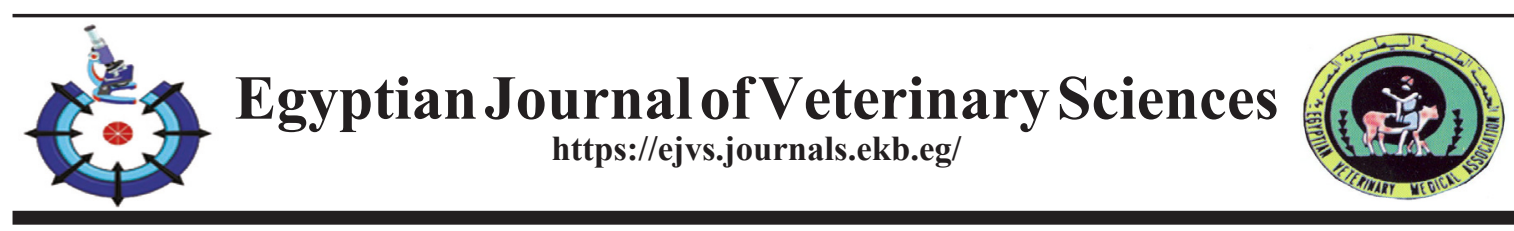

\title{
Study on Occurrence of Contagious Equine Metritis in the Genital Tract of Equine.
}

\author{
Mona M. Sobhy ${ }^{{ }^{*}}$, A. Fathi ${ }^{2}$, Kh.A. Abougazia ${ }^{1}$, M.R. Oshba ${ }^{3}$ and M.H.R. Kotb ${ }^{1}$ \\ 1 *Department of Reproductive Diseases, Animal Reproduction Research Institute, \\ Agriculture Research Centre (ARC), Cairo, Egypt. \\ ${ }^{2}$ ImmunityUnits, Animal Reproduction Research Institute, Agriculture Research \\ Centre (ARC), Cairo, Egypt. \\ ${ }^{3}$ Ultrasonography and Laparoscope Unit, Animal Reproduction Research Institute, \\ Agriculture Research Centre (ARC), Cairo, Egypt.
}

\begin{abstract}
CONTAGIOUS Equine Metritis (CEM) is a transmissible venereal disease of equine, causes infertility in mares and spontaneous abortion in pregnant ones. Theetiological agent of CEM is Gram negative bacteria; Taylorellaequigenitalis. In this study,a number of 45 clitoral swabswere collected from suspected mares and twenty swabs were fromurethral fossa of stallions. Swabs were kept cool during transportation on Amies with charcoal medium. At the lab, all swabs during 48 hours since they have been collected then cultured on tryptose chocolate blood agar (TBA) plates, and incubated at $37^{\circ} \mathrm{C}$ in microaerophilic atmosphere of $5 \%$ $10 \% \mathrm{CO}_{2}$ in hydrogen of 7 days. The suspected colonies have been examined for biochemical characters of catalase, oxidase and phosphatase.Allmareswere scannedby ultrasound scanner (Sono Scape sonar), vaginal and/or rectal, checked for the presence of any uterine fluid which may indicate the presence of infection. On the other hand, culture investigations revealed 2 (10\%) positive cases among stallions and $5(11.1 \%)$ mare's culture positive for T. equigenitalis. The bacterium is catalase, oxidase and phosphatase positive. The colonies were confirmed by immunofluorescent test and its sensitivity was $100 \%$.Ultrasound examination of three mare's uteri showing pyometra where their lumen measured 40.6- $57.3 \mathrm{~mm}$ fully filled with echogenic particles. While, the uteri of the other two mares showingendometritis which appearedas an echogenicuterine lumen measured $18.6 \mathrm{~mm}$ and $37.6 \mathrm{~mm}$ with echogenic particles scattered on it. Biosecurity practices can help in preventingspread of CEM by bacterial culture tests on breeding stallions prior to breeding season. Also, urethral swab for CEM testing should be a stallion's annual breeding exam. According to this study an ultrasound scan at the breeding season to check for the soundness of the mare uteri is strongly recommended.
\end{abstract}

Keywords: Contagious Equine Metritis, Mares, Stallion, Ultrasound.

\section{Introduction}

Contagious equine metritis (CEM) was first described in the United Kingdom (UK) in 1977, and then become world-wide [1].Contagious equine metritis is an inflammatory disease of the proximal and distal reproductive tract of the mare caused by Taylorellaequigenitalis, causing mares temporary infertile [2].

Taylorellaequigenitalis is a Gram-negative, microaerophiliccocco bacillus bacterium, transmitted during mating.Infected mares had a profuse, mucopurulent vaginal discharge up to $40 \%$ of affected mares due to inflammation

Corresponding auther: Mona M. Sobhy, E-mail:monagabr17@yahoo.com, Tel.01200208804

(Received 25/11/2019, accepted 09/01/2020)

DOI.10.21608/ejvs.2020.19942.1134

(C)2019 National Information and Documentation Center (NIDOC) 
of uterus and cervix, resulting in infertility in few days after breeding and return to estrus[3]. Acute infection cause mucoid inflammation of endometrium withobvious discharge from vulva seen 1-6 days after infection post-breeding [4].

CEM is rare abortions, but infected mares can produce subclinical carrier foals. Most mares are clitoral carriers and the poor hygienic measures during breeding may spread the organism. The sites of $T$. equigenitalis colonization are in the clitoral fossa [5].

Stallion is asymptomatic andcarries the organism on their external genitalia for a period of time [6]. Both mares and stallions become chronic carriers acting as a reservoir of $T$. equigenitalis and source of infection [7]. Infected stallions are passive carriers of the colonisedbacteria on their external genitalia where it invades urethra and sex glands, causing pus and contaminatedsemen [8].

The transmission is high with breeding, where the contaminated instruments and equipment's act as an indirect means of infection. The bacteria spread in semen collected for artificial insemination [9]. Organism has the fastidious nature and slow growth difficult to culture and requires multiple culture samples for one week [10].

The organism can be eliminated by treatment with systemic antibiotics at least 7 days or 21 days combined with antiseptic washing of the affected sites[11]. The infected equine can be treatedby chlorhexidine and applying ointments $0.2 \%$ nitrofurazone [12]. Diagnostic tests must be repeated 21 days after the end of treatment. Trimethoprim-sulfamethoxazole and application $1 \%$ silver sulfadiazine cream can be used. Fertility appears to return normal after treatment of horses [13]. The present study was aimedat assessingthe occurrence of Contagious Equine Metritis in equine by identification of infected carrier animals and on their treatment or elimination from breeding programs to avoid the introduction of the disease.

\section{Materials and Methods}

\section{Sampling}

From mares 45 clitoral swabs were collected, where 20 swabs were taken from the urethral fossaof stallions. All sanitary and hygienic measures were followed by using sterile saline and cotton to clean the areas of sample taken, and use new pair of disposable gloves for each animal. Swabs were kept on ice or at $4^{\circ} \mathrm{C}$, and delivered to a qualified laboratory within $24 \mathrm{hrs}$. transportation and plated out at labduring 48 hours after collection of samples. All swabs were transferred in a transport medium Amies with charcoal thenlabeledandkept under refrigeration conditions for variety of laboratory tests has been developedas described by Swerczek [14].

\section{Cultural and biochemical characteristics}

All swabs were cultured on plates of tryptose chocolate blood agar (TBA); by adding 5\% horse blood with a rich peptone agar, trimethoprim $1 \mu \mathrm{g} / \mathrm{ml}$, clindamycin $5 \mu \mathrm{g} / \mathrm{ml}$ and amphoteric in $\mathrm{B} 10 \mu \mathrm{g} / \mathrm{mlthen}$ cultured at $37^{\circ} \mathrm{C}$ and kept in microaerophilic atmosphere of $5 \%$ to $10 \% \mathrm{CO}_{2}$ in hydrogen during a minimum period of 7 days [15]. The suspected colonies were subjected to biochemical investigations with catalase, oxidase and phosphatase[16].

\section{Indirect immunofluorescence antibody tests (IFAT)}

The Pourquier IIF Taylorellaequigenitalis Test is an indirect immunofluore scence (IIF) test, a simple and cost-effective method based on the direct detection of Taylorellaequigenitalis for confirming colonies by IDEXX kits.

\section{Ultrasonography examination}

Vaginal and/or rectal examinations of 45 mares were carried out by ultrasound scanner (SonoScapeSonar) checking for presence of any uterine fluids which may indicate infection.

\section{Results}

By culture examination found 5 (11.1\%) positive cases of T. equigenitalis in mare and 2 $(10 \%)$ positive cases in stallion. The colonies are up to $2-3 \mathrm{~mm}$ in diameter, soft, full edge yellow / greyish colour produces, tiny and round after $48 \mathrm{~h}$. The colonies may be enlarged and turned whitish at $37^{\circ} \mathrm{C}$ with further incubation. The bacterium is nonmotile, catalase, oxidase and phosphatase positive for biochemical characteristics. The indirect immunofluore scenttest was applied to discriminate T. equigenitalis from T. asinigenitalis. This test constitutes a rapid, sensitive and specific tool for confirming presumptive colonies of $T$. equigenitalis (Fig.1).

The scanned of 45 mares with ultrasound scanner detected 3 cases of uterine pyometra which appears as lumen measured 40.6 - 57.3mm fully filled with echogenic particles (Image 1) and 2 mares affected with endometritisappearsas anechoic uterine lumen measured 18.6 mm- 37.6 $\mathrm{mm}$ with some echogenic particles (Image 2). 


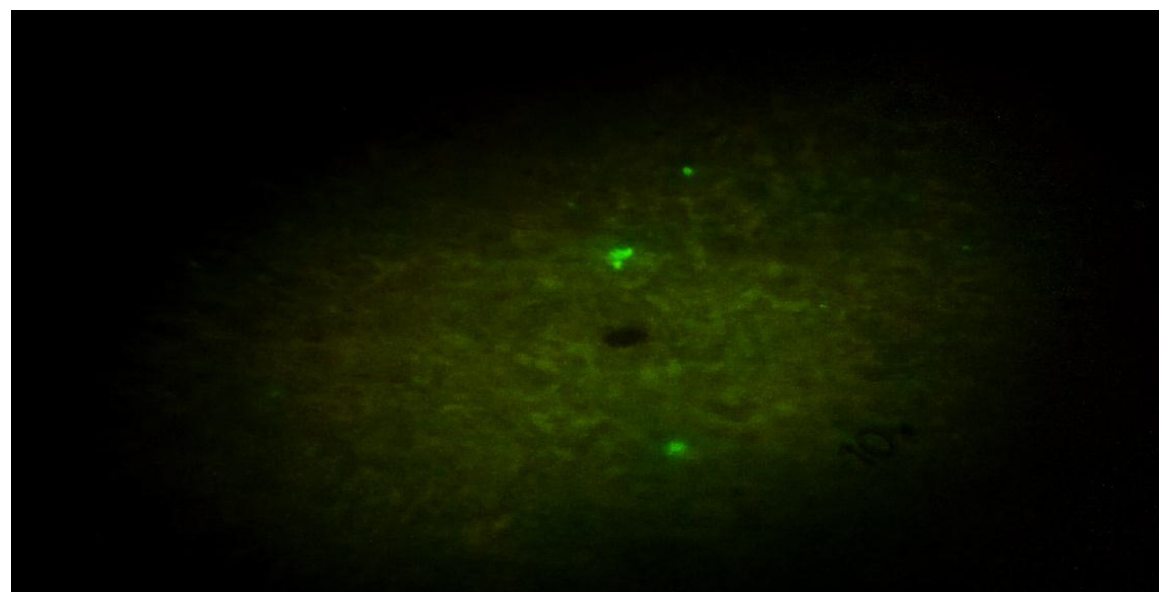

Fig. 1. Positive sample by indirect immunofluorescent test for T. equigenitalis under fluorescent microscope Zeiss at $10 \mathrm{X}$.



Image 1: Ultrasound image of mare uterus showing pyometra which appears as lumen measured $40.6-57.3 \mathrm{~mm}$ fully filled with echogenic particles.

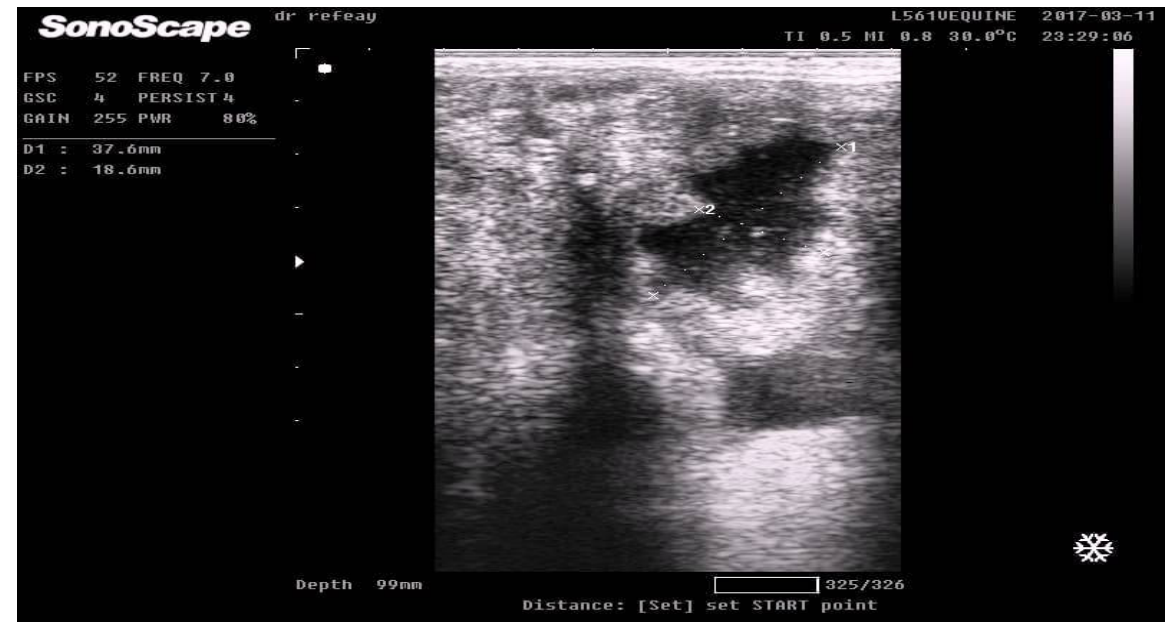

Image 2: Ultrasound image of mare uterus showing endometritis which appearsas anechoic uterine lumen measured $18.6 \mathrm{~mm}-37.6 \mathrm{~mm}$ with some echogenic particles. 


\section{Discussion}

Contagious equine metritis (CEM) is a contagious venereal disease of horses caused by Taylorella equigenitalis [17]. Culture positive was investigated in $2(10 \%)$ cases stallions and $5(11.1 \%)$ mares belonging to different localities in Egypt. These results agreed with previously demonstrated in United States with Timoney [18].

The colonies were confirmed for Taylorella equigenitalis by IDEXX indirect immunofluo rescent testkits (Fig.1) and discriminated bacterium from $T$. asinigenitalis. IFT sensitivity was $100 \%$ in samplesand its specificity $97.2 \%$ screened by bacteriological tests constitutes a satisfactory way to determine CEM status [19]

The scanning of 45 mares with ultrasound scanner detected $3(6.7 \%)$ uterine pyometra which appears as lumen measured $40.6-57.3 \mathrm{~mm}$ fully filled with echogenic particles (Image, 1) and 2 (4.4\%) affected with endometritis appears as measured 18.6 mm- 37.6 mm (Image, 2) [20].

The equine breeding industry depends on the health of the uterus, and without a healthy uterus a mare cannot successfully conceive or carry a foal to term [21]. In this study detected low prevalence of CME can be treated or eliminated from breeding. Bacterial infections of uterus are leading cause of subfertility and infertility in mares and represent a major economic loss to the equine industry. Infected mares affected bycervicitis, metritis, with vaginal and cervical discharges. Mares had a short estrus cycle and failed to conceive or give full-term foal, which may carry the organism [22]. Mares may remain infected for several months and chronically infected mares show no signs [23].

T. equigenitalis spread to stallions via indirect mechanisms at shared breeding and to mares via artificial insemination [17]. CEM should be a diagnostic consideration even where this organism is to be absent. Infected horses must be quarantined and treated with disinfectants and antibiotics for several weeks [24].

Biosecurity practices can prevent the spread of CEM by conducting bacterial culture tests on breeding stallions prior to breeding season[25]. Urethral swab for CEM testing must be annual breeding examfor stallion[26]. The use of the technique of ultrasonography and laboratory findings was very helpful and of great benefit, facilitated the selection of the suspected cases among the disease carriers and identify the endometritis in mare, that greatly saved time, effort and cost.

\section{Conclusion}

The control startsbefore reproductive season to know the status of the animal and improving hygienic measures to prevent the spread of infection among animals.

Control of CEM depends upon early identification of infected carrier horses, followed by treatment or elimination from breeding program. Horses over two years of age are quarantined and screened for T. equigenitalis.

The utmost preventing measures are:

- Stallions, teasers and mares should be examined for CEM before breeding by swabbing and testing at the laboratory.

- Strict hygienic measures should be applied during handling mares and stallions.

- Stop mating using the infected stallion.

- Isolate and treat the infected horse.

- Biosecurity measures during the daily handling.

- Clean and disinfect semen equipment between stallions.

- Keep records for horse movements and semen shipments.

Acknowledgment: I will be appreciating to stuff of immunity unit in Animal Reproduction Research Institute for their helpful and support during this research.

Funding statement: Research workers paid the full costs of the research.

Conflict of interest: We didn't found any problem during the work.

Ethical consideration: All studies described in this research were carried out at the department of Reproductive Diseases Laboratory, located at Animal Reproduction Research Institute, Agriculture Research Center,Giza, Egypt. Code No. 13/732/3/4/7. 


\section{References}

1. Sahu, S.P., Dardiri, A.H., Rommel, F.A. and Pierson, R.E. Survival of contagious equine metritis bacteria in transport media. Am. J. Vet. Res., 40, 1040-1042 (1979).

2. OIE (World Organization for Animal Health), Contagious Equine Metritis.http://www.oie.int/en/ scientific-expertise/reference-laboratories/list-oflaboratories/ 2018.

3. Fernie, D.S., Batty, I., Walker, P.D., Platt, H., Mackintosh, M.E. andSimpson,D.J.Observations on vaccine and post-infection immunity in contagious equine metritis. Res. Vet. Sci., 28, 362367 (1980).

4. Anzai, T, Kamada, M., Niwa, H., Eguchi, M., and Nishi,H.Contagious equine metritis eradicated from Japan.J. Vet. Med. Sci., 74 (4),519-22 (2012).

5. Schulman, M.L, May, C.E., Keys, B. and Guthrie, A.J. Contagious equine metritis: artificial reproduction changes the epidemiologic paradigm. Vet Microbiol. 167 (1-2), 2-8 (2013).

6. Timoney, P.J. Contagious equine metritis. In: Foreign Animal Diseases. $7^{\text {th }}$ ed. Boca Raton, FL: United States Animal Health Association. p. 225230 (2008).

7. CDFA Animal Health and Food Safety Services. Animal Health Branch. (2019).

8. Mead, B.J., Timoney, P.J., Donahue, J.M., Branscum, A.J., Ford, R. and Rowe,R. Initial occurrence of Taylorellaasinigenitalisand its detection in nurse mares, a stallion and donkeys in Kentucky. Prev. Vet. Med., 95, 292-296 (2010).

9. Klein, C., Donahue, J.M., Sells, S.F., Squires, E.L., Timoney, P.J., and Troedsson, M.H. Effect of antimicrobial-containing semen extender on risk of dissemination of contagious equine metritis. $J$. Am.Vet.Med. Assoc., 241 (7), 916-921 (2012).

10. Baverud, V., Nyström, C., and Johansson, K.E. Isolation and identification of Taylorellaasinigenitalisfrom the genital tract of a stallion, first case of a natural infection. Vet. Microbiol., 116, 294-300 (2006).

11. Jang, S.S., Donahue, J.M., Arata, A.B., Goris, J., Hansen, L.M., Earley, D.L., Vandamme, P.A.,Timoney, P.J., and Hirsh,D.C.Taylorellaasini genitalissp. A bacterium isolated from the genital tract of male donkeys (Equusasinus). Int. J. Syst. Evol. Microbiol. 51, 971-976 (2001).
12. Kristula, M.A. and Smith, B.I. Diagnosis and treatment of four stallions, carriers of the contagious metritis organism--case report. Theriogenology, 61, 595-601 (2004).

13. Katz, J.B., Evans, L.E., Hutto, D.L., SchroederTucker, L.C., Carew, A.M., Donahue, J.M., and Hirsh, D.C. Clinical, bacteriologic, serologic, and pathologic features of infections with atypical Taylorellaequigenitalisin mares. J. Am. Vet. Med. Assoc., 216, 1945-1948 (2000).

14. Swerczek, T.W. Inhibition of the CEM organism by the normal flora of the reproductive tract. Vet. Rec., 103, 125-129 (1978).

15. Platt, H. J.G. Atherton, D.J. Simpson, C.E.D., Taylor, R.O., Rosenthal, D.F. Brown, J.andWright, T.G. Genital infection in mares. Vet. Rec., 101, 2026 (1977).

16. HSC (Health Surveillance Centre). Complutense University, Spain. (2019).

17. Erdman, M.M., Creekmore, L.H., Fox, P.E., Pelzel, A.M., Porter-Spalding, B.A., Aalsburg, A.M., Cox, L.K., Morningstar-Shaw, B.R., and Crom, R.L. Diagnostic and epidemiologic analysis of the 2008-2010 investigation of a multi-year outbreak of contagious equine metritis in the United States. Prev. Vet. Med., 101(3-4),219-228 (2011).

18. Timoney, P.J. Horse species symposium: contagious equine metritis: an insidious threat to the horse breeding industry in the United States. J. Anim. Sci., 89 (5), 1552-1560 (2011).

19. Breuil, M.S.F., Duquesne, F., Sevin, C., Laugier, C. and Petry, S. Indirect immune-fluorescence test using polyclonal antibodies for the detection of $T$. equigenitalis. Res. Vet. Sci., 88, 369-371 (2010).

20. LeBlanc, M.M. and Causey, R.C. Clinical and subclinical endometritis in the mare: both threats to fertility. Reprod. Domest. Anim., 44 (3), 10-22 (2009).

21. Swerczek, T.W. and Caudle, A. B. Bacterial Causes of Subfertility and Abortion in the Mare. The Merck Veterinary Manual, $\mathbf{1 0}^{\text {th }}$ Ed. Merck and Co. Chapter 21, 168-172 (2014).

22. Gilbert, R.O. Contagious equine metritis. In: Kahn C.M., Line S., Aiello S.E. (Ed.), The Merck Veterinary Manual, $10^{\text {th }}$ ed. Whitehouse Station, NJ: Merck and Co. (2014).

Egypt. J. Vet. Sci. (special issue) (2019) 
23. Robert, O.G. Contagious Equine Metritis. Reproductive Medicine, Department of Clinical Sciences, College of Veterinary Medicine, Cornell University. MSD and the MSD Veterinary Manual (C) Merck Sharp \& Dohme Corp., a subsidiary of Merck \& Co., Inc., Kenilworth, NJ, USA (2019).

24. Luddy, S. and Kutzler, M.A.Contagious equine metritis within the United States: A review of the 2008 outbreak. J. Equine Vet. Sci., 30 (8), 393-400 (2010).
25. Timoney, P.J. Contagious equine metritis. Comp. Immunol.Microbiol. Infect. Dis., 19,199-204 (1996).

26. APHIS, (Animal and Plant Health Inspection Service).Contagious Equine Metritis.United States Department of Agriculture, 1-2 (2014).

$$
\begin{aligned}
& \text { المصرية عن تواجد مرض الآتهاب الرحمى الضارى للخيول فى الجهاز التناسلى للخيول } \\
& \text { منى محمد صبحى' ، أحمد فتحى" ، خالد عبد السميع ابو جازية" ، محمد رفاعى عشبه؛ و محمد حسام الدين }
\end{aligned}
$$

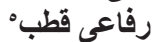

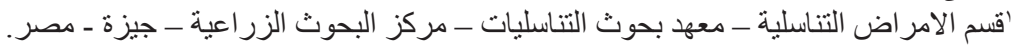

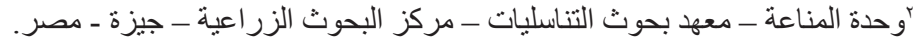

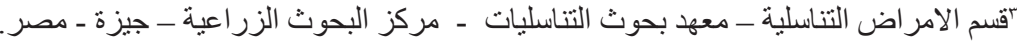

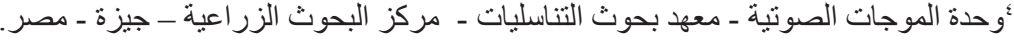

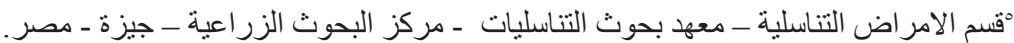

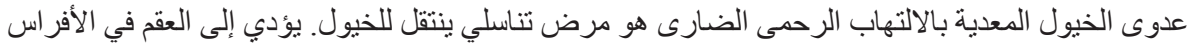

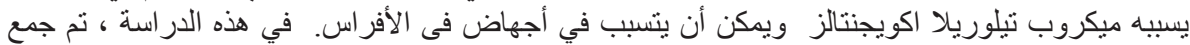

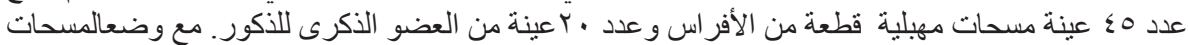

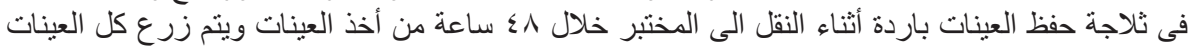

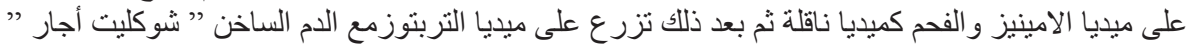

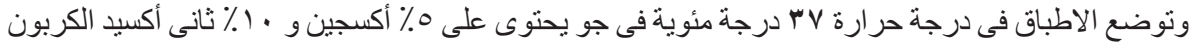

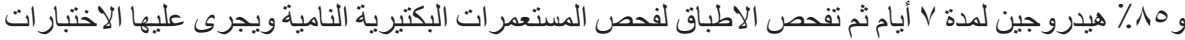

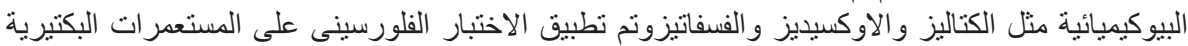

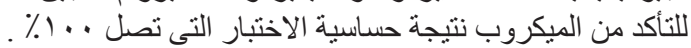

جميع الأفر اس تم فحصها باستخدام الموجات فوق الصوتية ، المهبلية / أو المستقيمية بو اسطة جهاز سونار

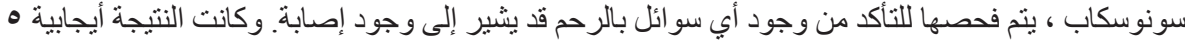

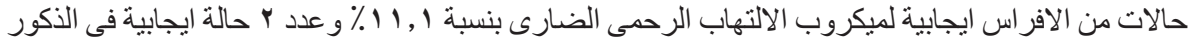

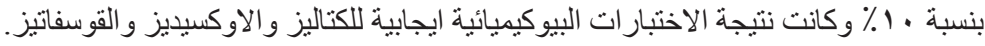

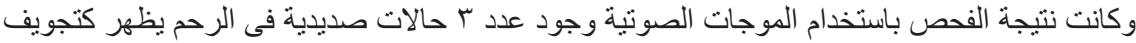

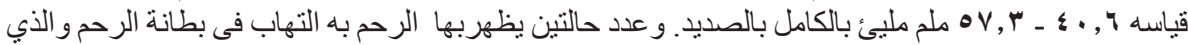

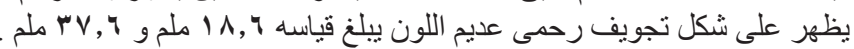

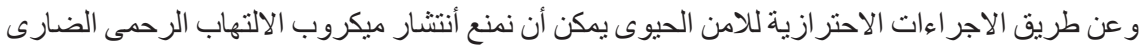

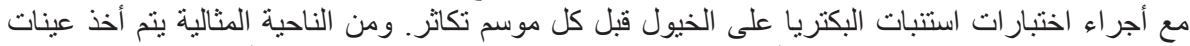

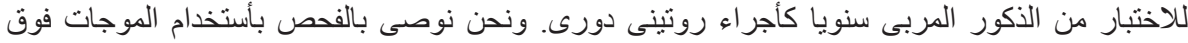

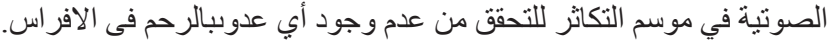

